Article

\title{
Quality of Life of Women after Giving Birth: Associated Factors Related with the Birth Process
}

\author{
Juan Miguel Martínez-Galiano ${ }^{1,2}$, Antonio Hernández-Martínez ${ }^{3,4}$, \\ Julián Rodríguez-Almagro ${ }^{3, *}$ (D) and Miguel Delgado-Rodríguez ${ }^{2,5}$ \\ 1 Department of Nursing, University of Jaen, 23071 Jaen, Spain; jgaliano@ujaen.es \\ 2 Consortium for Biomedical Research in Epidemiology and Public Health (CIBERESP), 28029 Madrid, Spain; \\ mdelgado@ujaen.es \\ 3 Department of Nursing of University of Castilla la Mancha, 13071 Ciudad Real, Spain; \\ antomatron@gmail.com \\ 4 Mancha-Centro Hospital, Alcázar de San Juan, 13600 Ciudad Real, Spain \\ 5 Department of Health Sciences, University of Jaen, 23071 Jaen, Spain \\ * Correspondence: julianj.rodriguez@uclm.es; Tel.: +34-676-683-843
}

Received: 24 January 2019; Accepted: 5 March 2019; Published: 7 March 2019

\begin{abstract}
The World Health Organization (WHO) considers quality of life a fundamental indicator. The effect of birth on women's long-term quality of life (QoL) has barely been studied. The purpose of this study was to determine the factors related with the pregnancy, delivery and puerperium, and assess women's QoL after giving birth. A cross-sectional study with Spanish puerperal women was carried out; it collected data on socio-demographic variables, obstetric variables, newborn data, and several quality of life parameters. An ad hoc online questionnaire, including SF-36 (validated instrument to measure QoL), was used. Crude mean differences (MD) and adjusted mean differences (aMD) were estimated by multiple linear regression. A total of 2990 women participated whose overall QoL lowered with time until three years postpartum $(p=0.045)$. Caesarean section $(\mathrm{aMD}=-3.61,95 \%$ confidence interval $(\mathrm{CI}):-5.07,-2.15)$, mother admitted to $\mathrm{ICU}(\mathrm{aMD}=-4.81$, 95\% CI: $-9.56,-2.68)$, newborn hospitalized (aMD $=-2.10,95 \% \mathrm{CI}:-4.31,-0.13$ ) or third / fourth degree perineal tears $(\mathrm{aMD}=-6.8795 \% \mathrm{CI}$ : $-9.93,-3.82)$ were detected as risk factors that affect negatively and significantly on postpartum QoL scores. Women's postpartum QoL worsens with time. Some determining factors negatively influence postpartum QoL: Caesarean section, a mother's admission to an intensive care unit (ICU) or a premature newborn.
\end{abstract}

Keywords: associated factors; birth; postpartum period; pregnancy; quality of life

\section{Introduction}

Quality of life (QoL) is a parameter that has been defined and recently taken into account as a health indicator. The World Health Organization (WHO) defines QoL as "the concept of an individual of its own status in life in relation to the culture and the system of values in which it lives, and in relation to its goals, standards and needs" [1].

Several instruments exist to assess QoL in different health and welfare aspects, which include: the SF-36 ((validated instrument to measure QoL) QoL in health questionnaire [2], the EuroQol-5D [3], the King's Health Questionnaire [4], the QoL questionnaire (WHOQOL-BREF) [5], or the Nottingham Health Profile (NHP) [6], among others.

The pregnancy, birth and postpartum period, and a child being born along with the new role of mother and the responsibilities that this entails, are significant periods in women's lives that entail major changes in their QoL due to physical, psychic and social repercussions [7-9]. 
Different aspects of the pregnancy, birth and postpartum process and QoL have been studied [10-16] but, as a literature review of 75 studies indicates, very few research works have evaluated QoL during pregnancy [14]. An Australian cohort study detected how the physical QoL of 355 women significantly worsened throughout pregnancy, in contrast mental QoL tended to improve, but not significantly so [10]. A Swedish study followed up a sample of 372 primiparous women during five years postpartum. This research related birth with the QoL score and some of its dimensions. Some of those worsened, such as their former health status, how they generally perceived their health, their disease resistance and also their health concerns [11]. For the 190 Japanese women who participated in a study into QoL during pregnancy, the subscale scores for "physical function", "physical role" and "bodily pain" significantly decreased throughout pregnancy, while no significant changes during pregnancy were noted for the "general health" and "mental health" subscales [15].

Given the importance that QoL has during the pregnancy, birth and postpartum process, and the recommendations made for future studies into this topic to design suitable strategies, policies and programmes to improve women's postpartum QoL, the aim to determine the factors related with the pregnancy, birth and postpartum process associated with postpartum QoL was proposed.

\section{Materials and Methods}

A cross-sectional study was conducted with women who gave birth in Spain in 2017.

This study was approved by the Ethics Committee in Clinical research (CEIC) of Mancha-Centro Hospital. Before the women completed the study questionnaire, they were given information about the study, its objectives, etc. They ticked a box if they wished to give their consent; i.e., they signed an ad hoc devised digital informed consent.

Births that resulted in antenatal fetal death and women aged under 18 years old were excluded.

A $5 \%$ alpha risk, a $10 \%$ beta risk (power $=90 \%$ ), an effect size of 0.02 points and a potential number of 10 predictors were applied to estimate sample size [17]. The minimum sample size was estimated at 1036 women.

\subsection{Sources of Information}

The authors designed an online questionnaire for data collection. It included 35 items (3 open, 32 closed questions) about obstetric results, clinical and socio-demographic characteristics, and newborn data. The validated instrument SF-36 $[2,18]$ was also used to measure QoL. The questionnaire had been formerly piloted and handed to women by the main women's associations, the Spanish Federation of Midwives Associations (FAME). In order to encourage women's participation its member associations and their midwives made the project known and helped facilitate it. Having selecting the subjects and having them sign the consent to participate, they received instructions to complete the questionnaire (self-completed), which they did when appropriate. A phone number and a chat service were used to answer any queries they had when answering the questionnaire.

The following variables were collected:

Our main dependent variable was the score obtained with the SF-36 QoL questionnaire.

The independent variables were: the mother's age, educational level, nationality, parity (primiparous or multiparous), health problems during pregnancy, previous caesarean section, twin pregnancy, birth type (vaginal or caesarean section), third/fourth degree perineal tears, involved episiotomy during birth, mother admitted to an intensive care unit (ICU) after giving birth, postpartum surgery, mother readmitted to hospital after being discharged, premature newborn, newborn hospitalized, breastfeeding, postpartum time (less than 1 year, 1-3 years, more than 3 years) and if the women's QoL was affected by different processes, except pregnancy, birth and postpartum. For this variable, we created a specific question/item in the questionnaire. The woman was asked what her perception was about whether or not it affected her socio-economic level, the presence of pathology or other factors that were not related to the pregnancy process on her quality of life. 


\subsection{Statistical Analysis Employed}

First of all, a descriptive analysis was run with absolute and relative frequencies for the categorical variables, and the mean with standard deviation (SD) for the quantitative variables. An analysis of variance (ANOVA) was used to compare the QoL scores according to their last postpartum time. To establish any relationship among the different factors and QoL, the crude mean difference (MD) of the scores was calculated by linear regression. Then the adjusted MD (aMD) was calculated by multiple linear regression following the SPSS forward and backward procedures by introducing the potential confounder variables into the analysis. Finally, for the estimation of the individual quality of life a simple calculator was developed with the Excel program. The final score was calculated by means of a linear regression equation. In this resource, the variables that were detected that had an association with the quality of life were included (Supplementary Table S1).

A $p<0.05$ was considered significant. All the analyses were performed with the SPSS v24.0 (SPSS Inc., Chicago, IL, USA) statistics package.

\subsection{Ethical Approval}

This study was approved by the Ethics Committee in Clinical Research (CEIC) of the Mancha-Centre Hospital with reference number ACT 2017.

\section{Results}

In this work, 2990 women participated: 59.1\% (1767) had studied at university, the pregnancies of $70.7 \%$ (2113) ended normally, 78.5\% (2257) had a normal vaginal birth, for 63.6\% (1901) no episiotomy was involved, $70.6 \%$ (2741) breastfed their infants and 66.5\% (1987) of the studied cases had spent more than one year during the intergenesic period, as Table 1 shows with its study population characteristics.

Table 1. Characteristics of the study population.

\begin{tabular}{ll}
\hline Variable & $\boldsymbol{n} \mathbf{( \% )}$ \\
\hline $\begin{array}{l}\text { Mother's age } \\
<3 \text { years }\end{array}$ & $1449(48.5)$ \\
$\geq 35$ years & $1541(51.5)$ \\
Educational level & \\
No studies & $7(0.2)$ \\
Primary education & $146(4.9)$ \\
Secondary education & $1070(35.8)$ \\
University education & $1767(59.1)$ \\
Nationality & \\
Spanish & $2886(96.5)$ \\
Other & $104(3.5)$ \\
Parity & \\
Primiparae & $1503(50.3)$ \\
Multiparae & $1487(49.7)$ \\
Health problems during pregnancy & \\
No & $2113(70.7)$ \\
Yes & $877(29.3)$ \\
Previous Caesarean section & \\
No & $2072(69.3)$ \\
Yes & $918(30.7)$ \\
Twin pregnancy & \\
No & $2870(96.0)$ \\
Type of Birth & $120(4.0)$ \\
Vaginal & \\
Caesarean section & $2257(75.5)$ \\
\hline & $733(24.5)$ \\
\hline
\end{tabular}


Table 1. Cont.

\begin{tabular}{ll}
\hline Variable & $\boldsymbol{n}(\mathbf{\%})$ \\
\hline Episiotomy & \\
No & $1901(63.6)$ \\
Yes & $1089(36.4)$ \\
Third/fourth degree perineal tears & \\
No & $2865(95.8)$ \\
Yes & $125(4.2)$ \\
Mother admitted to an ICU & \\
No & $2928(97.9)$ \\
Yes & $62(2.1)$ \\
Performing postpartum surgery & \\
No & $2921(97.7)$ \\
Yes & $69(2.3)$ \\
Readmitted to hospital after discharge & \\
No & $2893(96.8)$ \\
Yes & $97(3.2)$ \\
Premature newborn & \\
No & $2757(92.2)$ \\
Yes & $233(7.8)$ \\
Newborn hospitalised & \\
No & $2741(70.6)$ \\
Yes & $249(8.3)$ \\
Formula-fed & \\
Yo & $2112(70.6)$ \\
Time since last giving birth & $878(29.4)$ \\
Less than 1 year & \\
$1-3$ years & $1003(33.5)$ \\
More than 3 years & $1091(36.5)$ \\
\hline
\end{tabular}

Table 2 offers the overall QoL scores and the specific dimensions that form it at three specific time points: Before 1 year postpartum, 1-3 years postpartum and more than 3 years postpartum. We can see how QoL tends to worsen with time, as the overall QoL score indicates $(p=0.045)$, and also some of its dimensions, like overall health $(p<0.001)$, mental health $(p=0.005)$, etc.

Table 2. Overall scores for quality of life and dimensions according to time points.

\begin{tabular}{cccccc}
\hline \multirow{2}{*}{ Variable } & \multicolumn{3}{c}{ Time since Last Birth } & P-Value * & $\begin{array}{c}p \text {-Value * for Linear } \\
\text { Tendency }\end{array}$ \\
\cline { 2 - 4 } & $\begin{array}{c}\text { Less than 1 Year } \\
\text { Mean (SD) }\end{array}$ & $\begin{array}{c}\text { between 1-3 Years } \\
\text { Mean (SD) }\end{array}$ & $\begin{array}{c}\text { More than 3 Years } \\
\text { Mean (SD) }\end{array}$ & & \\
\hline Overall quality of life & $71.94(17.48)$ & $71.75(18.01)$ & $70.23(19.25)$ & 0.084 & 0.045 \\
Physical function & $89.46(20.72)$ & $91.27(18.76)$ & $89.11(22.58)$ & 0.040 & 0.786 \\
Physical role & $65.25(44.52)$ & $72.96(40,78)$ & $70.53(42.04)$ & $<0.001$ & 0.005 \\
Bodily pain & $85.34(22.77)$ & $84.99(23.87)$ & $83.40(24.67)$ & 0.168 & 0.079 \\
General health & $63.11(18.76)$ & $60.01(19.89)$ & $57.28(19.72)$ & $<0.001$ & $<0.001$ \\
Vitality & $51.72(23.00)$ & $51.27(22.39)$ & $51.23(23.66)$ & 0.868 & 0.632 \\
Social role functioning & $75.70(25.99)$ & $74.68(26.98)$ & $74.41(26.08)$ & 0.525 & 0.284 \\
Emotional role & $80.61(36.98)$ & $76.58(39.83)$ & $73.88(41.53)$ & 0.001 & $<0.001$ \\
Mental health & $64.31(18.08)$ & $62.23(18.58)$ & $61.96(18.97)$ & 0.009 & 0.005 \\
\hline
\end{tabular}

* Analysis of variance; SD, standard deviation.

Among the other variables in Table 3, we find having completed secondary (aMD = 14.10, 95\% CI: $1.55,26.65)$ and university $(\mathrm{aMD}=18.70,95 \% \mathrm{CI}: 6.15,31.25)$ education helped to obtain a higher postpartum QoL score. Caesarean section (aMD $=-3.61,95 \%$ CI: $-5.07,-2.15$ ), mother admitted to an ICU (aMD $=-4.81,95 \% \mathrm{CI}:-9.56,-2.68)$, newborn hospitalized $(\mathrm{aMD}=-2.10,95 \%$ CI: $4.31,-0.13$ ), third/fourth degree perineal tears (aMD $=-6.87,95 \% \mathrm{CI}:-9.93,-3.82$ ) or involved episiotomy $(\mathrm{aMD}=-4.81,95 \% \mathrm{CI}$ : $-9.56,-2.68)$ while giving birth were risk factors that significantly and negatively affected the postpartum QoL score. 
Table 3. Factors associated with postpartum quality of life.

\begin{tabular}{|c|c|c|c|}
\hline Variable & Quality of Life Scores Mean (SD) & MD $95 \% \mathrm{CI} *$ & aMD $95 \% C I * *$ \\
\hline \multicolumn{4}{|l|}{ Mother's age } \\
\hline$<35$ years & $71.84(18.04)$ & (ref.) & (ref.) \\
\hline$\geq 35$ years & $70.90(18.39)$ & $-0.93(-2.24,0.37)$ & $-1.24(-2.55,0.08)$ \\
\hline \multicolumn{4}{|l|}{ Level of education } \\
\hline No studies & $60.09(23.27)$ & (ref.) & (ref.) \\
\hline Primary studies & $66.62(19.94)$ & $6.53(-7.19,20.25)$ & $12.42(-0.39,25.24)$ \\
\hline Secondary studies & $68.94(19.61)$ & $8.85(-4.59,22.30)$ & $14.10(1.55,26.65)$ \\
\hline University studies & $73.26(16.90)$ & $13.17(-0.26,26.59)$ & $18.70(6.15,31.25)$ \\
\hline \multicolumn{4}{|l|}{ Nationality } \\
\hline Spanish & $71.48(18.16)$ & (ref.) & \\
\hline Not Spanish & $67.93(19.60)$ & $-3.55(-7.12,0.01)$ & \\
\hline \multicolumn{4}{|l|}{ Parity } \\
\hline Primiparae & $70.25(18.54)$ & (ref.) & (ref.) \\
\hline Multiparae & $72.48(17.84)$ & $2.23(0.93,3.54)$ & $1.77(0.53,3.02)$ \\
\hline \multicolumn{4}{|c|}{ Health problems during pregnancy } \\
\hline No 1 & $71.84(18.60)$ & (ref.) & (ref.) \\
\hline \multirow{2}{*}{\multicolumn{4}{|c|}{ Previous caesarean section }} \\
\hline & & & \\
\hline No & $72.41(17.82)$ & (ref.) & \\
\hline Yes & $68.98(18.90)$ & $-3.44(-3.85,-2.03)$ & \\
\hline \multicolumn{4}{|l|}{ Twin pregnancy } \\
\hline No & $71.40(18.18)$ & (ref.) & \\
\hline Yes & $70.28(19.16)$ & $-1.13(-4.46,2.20)$ & \\
\hline \multicolumn{4}{|l|}{ Birth type } \\
\hline Vaginal & $72.46(17.77)$ & (ref.) & (ref.) \\
\hline Caesarean section & $67.95(19.19)$ & $-4.51(-6.02,-2.99)$ & $-3.61(-5.07,-2.15)$ \\
\hline \multicolumn{4}{|c|}{ Third/fourth degree perineal tears } \\
\hline No & $71.66(18.07)$ & (ref.) & (ref.) \\
\hline Yes & $64.46(20.29)$ & $-7.20(-10.45,-3.94)$ & $-6.87(-9.93,-3.82)$ \\
\hline \multicolumn{4}{|l|}{ Episiotomy } \\
\hline No & $71.32(18.26)$ & (ref.) & \\
\hline Yes & $71.42(18.18)$ & $0.10(-1.26,1.46)$ & \\
\hline \multicolumn{4}{|c|}{ Mother admitted to an ICU } \\
\hline No & $71.54(18.08)$ & (ref.) & (ref.) \\
\hline Yes & $62.49(22.53)$ & $-9.06(-13.63,-4.48)$ & $-4.81(-9.56,-2.68)$ \\
\hline \multicolumn{4}{|c|}{ Performing postpartum surgery } \\
\hline No & 71.49 (18.17) & (ref.) & \\
\hline Yes & $65.75(19.79)$ & $-5.74(-10.09,-1.39)$ & \\
\hline \multicolumn{4}{|c|}{ Readmitted to hospital after discharge } \\
\hline No & $71.57(18.08)$ & (ref.) & (ref.) \\
\hline Yes & $65.07(21.30)$ & $-6.50(-10.18,-2.82)$ & $-6.12(-9.14,-0.47)$ \\
\hline \multicolumn{4}{|l|}{ Premature newborn } \\
\hline No & $71.66(18.07)$ & (ref.) & \\
\hline Yes & $67.74(19.65)$ & $-3.92(-6.35,-1.48)$ & \\
\hline \multicolumn{4}{|c|}{ Newborn hospitalized } \\
\hline No & $71.65(17.96)$ & (ref.) & (ref.) \\
\hline Yes & $68.10(20.66)$ & $-3.55(-5.92,-1.19)$ & $-2.10(-4.31,-0.13)$ \\
\hline \multicolumn{4}{|l|}{ Formula-fed } \\
\hline No & $72.26(17.48)$ & (ref.) & \\
\hline Yes & $69.19(19.75)$ & $-3.07(-4.50,-1.64)$ & \\
\hline \multicolumn{4}{|c|}{ Time since last given birth } \\
\hline Less than 1 year & $71.94(17.48)$ & 1 (ref.) & (ref.) \\
\hline $1-3$ years & $71.75(18.01)$ & $-0.19(-1.75,1.37)$ & $1.65(0.18,3.11)$ \\
\hline More than 3 years & $70.23(19.25)$ & $-1.71(-3.35,-0.06)$ & $1.20(-0.42,2.81)$ \\
\hline \multicolumn{4}{|c|}{$\begin{array}{l}\text { Quality of life affected by problems not related } \\
\text { with pregnancy, birth and postpartum }\end{array}$} \\
\hline No & $74.67(16.64)$ & 1 (ref.) & (ref.) \\
\hline Yes & $60.99(19.08)$ & $\begin{array}{l}-13.69(-15.13 \\
-12.24)\end{array}$ & $\begin{array}{l}-13.52(-14.94, \\
-12.09)\end{array}$ \\
\hline
\end{tabular}

* MD: Crude mean differences. ${ }^{* *}$ aMD: Mean differences adjusted by level of education, mother's age, parity, problems during pregnancy, birth type, third/fourth degree perineal tears, mother admitted to an ICU, postpartum surgery, mother readmitted to hospital after discharge, newborn hospitalized, intergenesic period, quality of life affected by problems unrelated to pregnancy, birth and postpartum; (ref.): reference.

As an example of how the resource that has been created to calculate the quality of life of women in the postpartum period would work: The case of a woman over 35 years old, with secondary studies, multipara, with problems during pregnancy, with a cesarean delivery, without perineal tears type III/IV, without admission to the ICU, without hospital admission after discharge, with admission of the newborn, without affecting their quality of life due to other problems other than pregnancy, childbirth and puerperium would have to solve the following equation and that its delivery occurred between 1 and 3 years.

Score SF-36 $=($ Cte $=58.69)+(($ age $\geq 35$ years $=1) \times-1.24)+(($ level education secondary $=1) \times$ $14.10)+(($ multipara $=1) \times 1.77)+(($ health problems during pregnancy $=1) \times-2.42)+(($ caesarean section $=1) \times-3.61)+(($ third $/$ fourth degree perineal tears $=0) \times-6.87)+(($ mother admitted to an 
ICU $=0) \times-4.81)+(($ readmitted to hospital after discharge $=0) \times-6.12)+(($ newborn hospitalized $=$ $1) \times-2.10)+(($ Quality of life affected by problems not related with pregnancy, birth and postpartum $=0) \times-13.52)+(($ time since last giving birth: $1-3$ years $=1) \times 1.64)$. Score SF-36 = 66.8 points. (Figure 1).

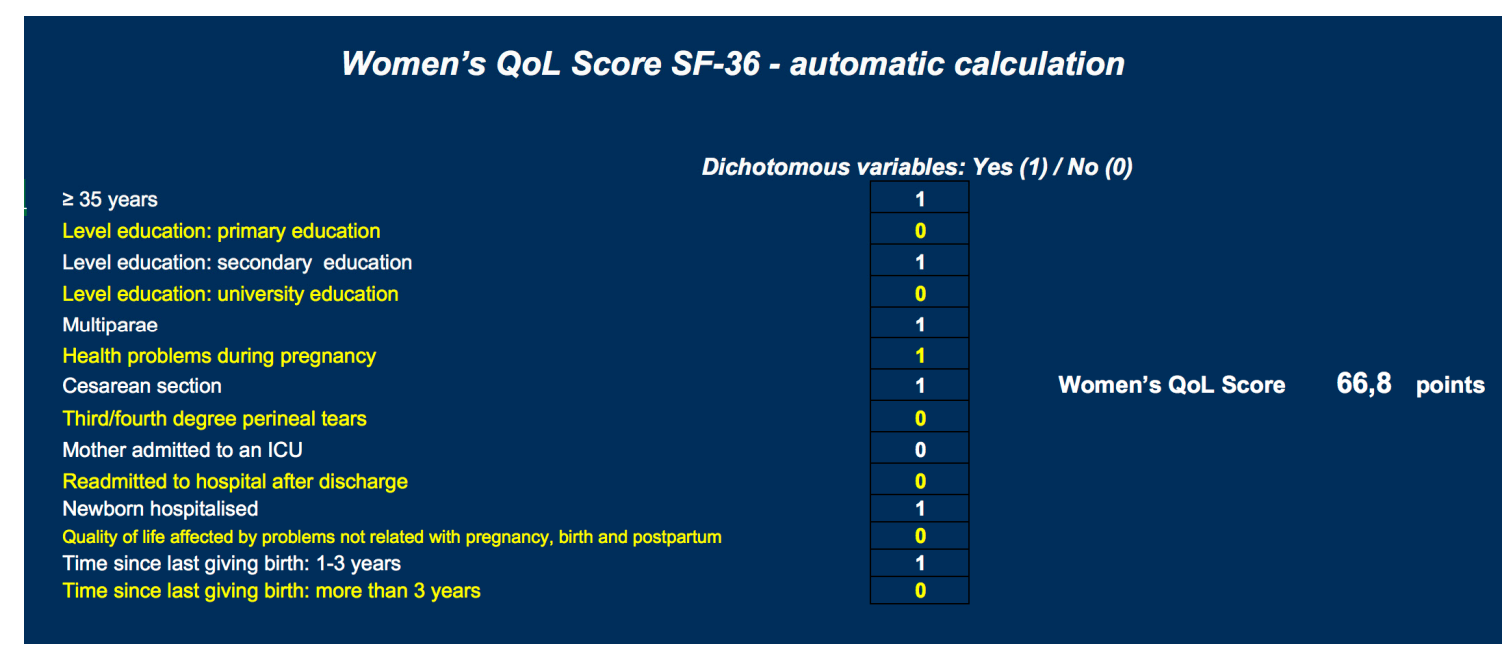

Figure 1. Score obtained in the SF-36 of the example created to explain the operation of the calculator.

\section{Discussion}

The overall QoL score of those women affected by maternity lowered with time. Some dimensions at $<1$ year postpartum, e.g., the "emotional role", scored well, but then significantly lowered at 1-3 years to then increase after three years postpartum. Some dimensions, e.g., the vitality score, barely changed, while others, e.g., the "physical role", obtained higher scores at 1-3 years postpartum, before dropping at three years, but were higher than during the initial postpartum period. Having had a higher education level was identified as a factor that facilitated women obtaining a higher postpartum QoL score. Caesarean section, third/fourth degree perineal tears while giving birth, involved episiotomy, having a premature newborn, the mother being admitted to an ICU, hospital readmission or the newborn being hospitalized were factors associated with women obtaining a lower postpartum QoL score.

A priori, the use of the calculator is designed for the reference population. However, it can be useful at a global level, as it provides the basis for a study that can be carried out in other populations. In this way, it would be possible to include in the resource those variables suitable for each population, as occurs with a very generalized practice: the validation of questionnaires. In addition, the obtained results could be compared between different populations.

No information was collected about depression during pregnancy and/or postpartum. The presence of this pathology can have an important effect on the quality of life of women in the postpartum period but in our study we could not associate it because this information was not available. The association of factors unrelated to the process of pregnancy and childbirth such as, economic level, etc., with the quality of life was determined independently with a specific question. This variable was used to adjust the score in the multivariate model. It is evident that the influence of the quality of life that a woman has, without taking into account the factors of the process of pregnancy and childbirth, can determine significantly the quality of life of the woman in the postpartum period. To avoid confusion of this variable on our results, we decided to adjust for it.

If there was a selection bias associated with non-response, it did not influence the results. The sample is representative of the Spanish population. Therefore, we think that women who did not respond, a priori, there are no reasons to think that they had done it in a different way to those who did respond. No information bias is likely to exist: the data collected combined with the questionnaire 
setup did not require a high educational level as was simply described. The data collection was carried out in a short time interval, we consider that the possible forgetfulness would have minimally affected the results because women perfectly know and remember the information about their birth process.

This study has its strong points: a large sample size, women from different geographical areas and is representative of the Spanish population. The instrument we used was the validated SF-36 questionnaire [2] as it has been used with pregnant Spanish women [19].

Most previous studies [19-28] refer to QoL during pregnancy and a short postpartum period, e.g., six weeks or six months, but have not dealt with long-term QoL as our results do, which measure QoL up to three years postpartum. Our results overall indicate QoL loss during the 1-3 year postpartum period compared to the first postpartum year. The score lowered again at three years postpartum. This poorer QoL falls in line with what Parks and Choi detected in their study conducted in South Korea with 5146 women aged more than 50 years. These authors identified an association of different parameters related to the pregnancy, birth and postpartum process and QoL [29]. The "physical role" dimension increased the score as the postpartum time prolonged (1-3 years), but it lowered at three years postpartum. All the dimensions lowered the score with time, but only significantly so for general health, the emotional role and mental health.

The mother's age $\geq 35$ years did not come over as a QoL-related factor, which contrasts with what Parks and Choi found because they identified the mother's younger age at child birth as a determining factor for worse QoL [29]. Another study included three clinical trials (DIGITAT, HYPITAT and WOMB) and did not associate the mother's age with QoL [27], which is in line with our results.

Among the factors identified as being predisposed to better QoL during the postpartum period, our results associated with women having secondary or university educations as opposed to those with no higher education. Yet other authors have found no such association [27]. This could perhaps be explained by having higher education implying better self-perceived health [30]. We found no association between women's nationality and postpartum QoL, as other authors have done [27].

The parity reflected in our results was associated with postpartum QoL, unlike what Prick et al. reported [27], that parity had no impact on postpartum QoL, but discussed by other authors [20,21,29] as they detected this association. However, Bai et al. [21] found that nulliparity negatively affected postpartum QoL, while Park and Choi [29] stated that multiparity was a determining factor for lower QoL.

Having health problems during pregnancy, like high blood pressure, nausea, anxiety and gestational diabetes, was another predisposing factor for worse postpartum QoL in our study, which coincides with other research results $[20,21,27]$. Caesarean section was also associated with worse postpartum QoL, which agrees with other works [27]. Nonetheless, Triviño-Juárez et al. [19] did not identify birth type as a factor that affected postpartum QoL in their Spanish study conducted with 546 women.

We observed how third/fourth degree perineal tears and involved episiotomy were associated with worse postpartum QoL, while others found no such relation [27]. However, their studies did not distinguish among different perineal lesion types, which our study did, but considered more severe perineal lesions that cause greater discomfort [31,32].

Similar to Prick et al. [27], newborn hospitalization and the mother being readmitted to hospital after being discharged, which falls in line with Fobelets et al. [26], and the mother being admitted to an ICU, which agrees with Pia et al. [24], were identified in our results as determining factors of worse postpartum QoL. The outcomes reported by Seppänen et al. [25] informed that the QoL of the women admitted to an ICU at six months postpartum tended to be similar scores to those given by the general population.

The gestational age at which women gave birth was also identified as a risk factor for a worse QoL score, which agrees with other studies [22,33]. 
The way babies were fed was studied. The women with formula-fed babies did not obtain worse QoL scores than those who breast-fed, which contrasts with what Triviño-Juárez et al. [28] identified as these authors associated breast feeding with a better QoL at six weeks postpartum.

Having a poor QoL before pregnancy due to factors unrelated to the pregnancy, birth and postpartum process was also identified as a predisposing factor for low postpartum QoL scores, which coincides with Fobelet et al. [26]. The women with a low QoL before being pregnant, for non-related to pregnancy reasons, birth and postpartum period, could be affected by this process because it is a stressful situation [20] that could affect negatively to further worsen or aggravate their QoL.

In Table S1 of the Supplemental Material, there is a calculator that can be used by professionals to include required information and individually calculate women's QoL scores, which is useful for identifying risk populations.

\section{Conclusions}

As a conclusion, postpartum women obtain QoL scores that lower with postpartum time. Certain factors are related with the pregnancy, birth and postpartum period, such as type of birth, a pre-term newborn, health problems during pregnancy, etc., that negatively impact women's QoL. Healthcare policies and perinatal health programs must bear these factors in mind to set up measures in order to prevent and improve women's postpartum QoL.

Supplementary Materials: The following are available online at http://www.mdpi.com/2077-0383/8/3/324/s1, Table S1: Instrument to automatic calculation of Women's QoL Score SF-36.

Author Contributions: Conceptualization, J.M.M.-G. and A.H.-M.; methodology, J.M.M.-G. and M.D.-R.; formal analysis, A.H.-M. and J.R.-A.; writing-original draft preparation, J.M.M.-G. and M.D.-R.; writing-review and editing, A.H.-M. and J.R.-A.; supervision, J.M.M.-G. and A.H.-M.; project administration, J.R.-A.

Conflicts of Interest: The authors declare no conflicts of interest.

\section{References}

1. WHO. The World Health Organization Quality of Life assessment (WHOQOL): Position paper from the World Health Organization. Soc. Sci. Med. 1995, 41, 1403-1409. [CrossRef]

2. Vilagut, G.; Ferrer, M.; Rajmil, L.; Rebollo, P.; Permanyer-Miralda, G.; Quintana, J.M.; Santed, R.; Valderas, J.M.; Ribera, A.; Domingo-Salvany, A.; et al. The Spanish version of the Short Form 36 Health Survey: A decade of experience and new developments. Gac. Sanit. 2005, 19, 135-150. [CrossRef] [PubMed]

3. Herdman, M.; Badia, X.; Berra, S. EuroQol-5D: A simple alternative for measuring health-related quality of life in primary care. Aten. Primaria 2001, 28, 425-430. [CrossRef]

4. Romero-Cullerés, G.; Sánchez-Raya, J.; Conejero-Sugrañes, J.; González-Viejo, M.Á. Validación de la versión española del cuestionario King's Health para la evaluación de la calidad de vida relacionada con la incontinencia urinaria en pacientes con lesión medular. Med. Clin. 2011, 137, 491-494. (In Spanish) [CrossRef] [PubMed]

5. Espinoza, I.; Osorio, P.; Torrejón, M.J.; Lucas-Carrasco, R.; Bunout, D. Validation of the WHOQOL-BREF quality of life questionnaire among Chilean older people. Rev. Med. Chil. 2011, 139, 579-586. [CrossRef] [PubMed]

6. Baghirzada, L.; Downey, K.N.; Macarthur, A.J. Assessment of quality of life indicators in the postpartum period. Int. J. Obstet. Anesth. 2013, 22, 209-216. [CrossRef] [PubMed]

7. Jomeen, J.; Martin, C. Perinatal quality of life: Is it important for childbearing women? Pract. Midwife 2012, 15, 30-34. [PubMed]

8. Darvill, R.; Skirton, H.; Farrand, P. Psychological factors that impact on women's experiences of first-time motherhood: A qualitative study of the transition. Midwifery 2010, 26, 357-366. [CrossRef] [PubMed]

9. Maroto-Navarro, G.; García-Calvente, M.D.; Mateo-Rodríguez, I. El reto de la maternidad en España: Dificultades sociales y sanitarias. Gac. Sanit. 2004, 18, 13-23. [CrossRef] [PubMed] 
10. Schubert, K.O.; Air, T.; Clark, S.R.; Grzeskowiak, L.E.; Miller, E.; Dekker, G.A.; Baune, B.T.; Clifton, V.L. Trajectories of anxiety and health related quality of life during pregnancy. PLoS ONE 2017, 12, e0181149. [CrossRef] [PubMed]

11. Carlander, A.-K.K.; Andolf, E.; Edman, G.; Wiklund, I. Health-related quality of life five years after birth of the first child. Sex. Reprod. Healthc. 2015, 6, 101-107. [CrossRef] [PubMed]

12. Álvarez Silvares, E.; de Diego Suárez, M.; Almazán Ortega, R.; González González, A.; Rodríguez Núñez, R. Influencia de la gestación de bajo riesgo en la calidad de vida relacionada con la salud percibida por las gestantes. Prog. Obs. Ginecol. 2008, 51, 4-14. (In Spanish) [CrossRef]

13. Hama, K.; Takamura, N.; Honda, S.; Abe, Y.; Yagura, C.; Miyamura, T.; Obama, M.; Morisaki, M.; Imamura, S.; Aoyagi, K. Evaluation of Quality of Life in Japanese Normal Pregnant Women. Acta Med. Nagasaki. 2008, 52, 95-99.

14. Morin, M.; Vayssiere, C.; Claris, O.; Irague, F.; Mallah, S.; Molinier, L.; Matillon, Y. Evaluation of the quality of life of pregnant women from 2005 to 2015. Eur. J. Obstet. Gynecol. Reprod. Biol. 2017, 214, 115-130. [CrossRef] [PubMed]

15. Yamaguchi, K.; Suganuma, N.; Ohashi, K. Quality of life evaluation in Japanese pregnant women with striae gravidarum: A cross-sectional study. BMC Res. Notes 2012, 5, 450. [CrossRef] [PubMed]

16. Kazemi, F.; Nahidi, F.; Kariman, N. Exploring factors behind pregnant women's quality of life in Iran: A qualitative study. Electron. Physician 2017, 9, 5991-6001. [CrossRef] [PubMed]

17. Cohen, J. Statistical Power Analysis for the Behavioral Sciences; Academic Press: Cambridge, MA, USA, 1977.

18. Alonso, J.; Regidor, E.; Barrio, G.; Prieto, L.; Rodríguez, C.; de la Fuente, L. Population reference values of the Spanish version of the Health Questionnaire SF-36. Med. Clin. 1998, 111, 410-416.

19. Triviño-Juárez, J.M.; Romero-Ayuso, D.; Nieto-Pereda, B.; Forjaz, M.J.; Criado-Álvarez, J.J.; Arruti-Sevilla, B.; Avilés-Gamez, B.; Oliver-Barrecheguren, C.; Mellizo-Díaz, S.; Soto-Lucía, C.; et al. Health related quality of life of women at the sixth week and sixth month postpartum by mode of birth. Women Birth 2017, 30, $29-39$. [CrossRef] [PubMed]

20. Chang, S.-R.; Chen, K.-H.; Lin, M.-I.; Lin, H.-H.; Huang, L.-H.; Lin, W.-A. A repeated measures study of changes in health-related quality of life during pregnancy and the relationship with obstetric factors. J. Adv. Nurs. 2014, 70, 2245-2256. [CrossRef] [PubMed]

21. Bai, G.; Raat, H.; Jaddoe, V.W.V.; Mautner, E.; Korfage, I.J. Trajectories and predictors of women's health-related quality of life during pregnancy: A large longitudinal cohort study. PLOS ONE 2018, 13, e0194999. [CrossRef] [PubMed]

22. Calou, C.G.; de Oliveira, M.F.; Carvalho, F.H.; Soares, P.R.; Bezerra, R.A.; de Lima, S.K.; Antezana, F.J.; de Souza Aquino, P.; Castro, R.C.; Pinheiro, A.K. Maternal predictors related to quality of life in pregnant women in the Northeast of Brazil. Health Qual. Life Outcomes 2018, 16, 109. [CrossRef] [PubMed]

23. Van den Bosch, A.A.; Goossens, M.; Bonouvrié, K.; Winkens, B.; Nijhuis, J.G.; Roumen, F.J.; Wassen, M.M. Maternal quality of life in routine labor epidural analgesia versus labor analgesia on request: Results of a randomized trial. Qual. Life Res. 2018, 27, 2027-2033. [CrossRef] [PubMed]

24. Seppänen, P.; Sund, R.; Ala-Kokko, T.; Roos, M.; Uotila, J.; Helminen, M.; Suominen, T. Obstetric patients' health-related quality of life before and after intensive care. Aust. Crit. Care 2018. [CrossRef] [PubMed]

25. Seppänen, P.M.; Sund, R.T.; Ala-Kokko, T.I.; Uotila, J.T.; Helminen, M.T.; Suominen, T.M. Health-related quality of life after obstetric intensive care admission: Comparison with the general population. J. Crit. Care 2018, 43, 276-280. [CrossRef] [PubMed]

26. Fobelets, M.; Beeckman, K.; Buyl, R.; Daly, D.; Sinclair, M.; Healy, P.; Grylka-Baeschlin, S.; Nicoletti, J.; Gross, M.M.; Morano, S.; et al. Mode of birth and postnatal health-related quality of life after one previous cesarean in three European countries. Birth 2018, 45, 137-147. [CrossRef] [PubMed]

27. Prick, B.W.; Bijlenga, D.; Jansen, A.G.; Boers, K.E.; Scherjon, S.A.; Koopmans, C.M.; van Pampus, M.G.; Essink-Bot, M.L.; van Rhenen, D.J.; Mol, B.W.; et al. Determinants of health-related quality of life in the postpartum period after obstetric complications. Eur. J. Obs. Gynecol. Reprod. Biol. 2015, 185, 88-95. [CrossRef] [PubMed]

28. Triviño-Juárez, J.M.; Nieto-Pereda, B.; Romero-Ayuso, D.; Arruti-Sevilla, B.; Avilés-Gámez, B.; Forjaz, M.J.; Oliver-Barrecheguren, C.; Mellizo-Díaz, S.; Soto-Lucía, C.; Plá-Mestre, R. Quality of life of mothers at the sixth week and sixth month post partum and type of infant feeding. Midwifery 2016, 34, 230-238. [CrossRef] [PubMed] 
29. Park, S.; Choi, N.-K. The relationships between timing of first childbirth, parity, and health-related quality of life. Qual. Life Res. 2018, 27, 937-943. [CrossRef] [PubMed]

30. Borgonovi, F.; Pokropek, A. Education and Self-Reported Health: Evidence from 23 Countries on the Role of Years of Schooling, Cognitive Skills and Social Capital. PLoS ONE 2016, 11, e0149716. [CrossRef] [PubMed]

31. Islam, A.; Hanif, A.; Ehsan, A.; Arif, S.; Niazi, S.K.; Niazi, A.K. Morbidity from episiotomy. J. Pak. Med. Assoc. 2013, 63, 696-701. [PubMed]

32. Priddis, H.; Schmied, V.; Dahlen, H. Women's experiences following severe perineal trauma: A qualitative study. BMC Womens Health 2014, 14, 32. [CrossRef] [PubMed]

33. Amorim, M.; Silva, S.; Kelly-Irving, M.; Alves, E. Quality of life among parents of preterm infants: A scoping review. Qual. Life Res. 2018, 27, 1119-1131. [CrossRef] [PubMed]

(C) 2019 by the authors. Licensee MDPI, Basel, Switzerland. This article is an open access article distributed under the terms and conditions of the Creative Commons Attribution (CC BY) license (http://creativecommons.org/licenses/by/4.0/). 